\title{
Electroplated Fe films prepared from a deep eutectic solvent
}

\author{
T. Yanai, ${ }^{1, a)}$ K. Shiraishi, ${ }^{1}$ T. Shimokawa, ${ }^{1}$ Y. Watanabe,${ }^{1}$ T. Ohgai, ${ }^{1}$ M. Nakano, ${ }^{1}$ K. Suzuki, ${ }^{2}$ \\ and $\mathrm{H}$. Fukunaga ${ }^{1}$ \\ ${ }^{1}$ Graduate School of Engineering, Nagasaki University, Nagasaki 852-8521, Japan \\ ${ }^{2}$ Department of Material Engineering, Monash University, Clayton, VIC 3800, Australia
}

(Presented 6 November 2013; received 23 September 2013; accepted 21 January 2014; published online 4 April 2014)

\begin{abstract}
Electroplating of Fe films was carried out from choline chloride-ethylene glycol types of DES (Deep Eutectic Solvent). We investigated magnetic properties of the plated Fe films and evaluated the productivity for the electroplating process. Consequently, we found that surface morphology and current efficiency of the plated films were affected by the bath temperature. We obtained the Fe films with relatively smooth surface and high current efficiency in the bath temperature range from 70 to $110^{\circ} \mathrm{C}$. The deposition rate for our process depended on the current density, and we obtained high deposition rate value of approximately $120 \mu \mathrm{m} / \mathrm{h}$. We also obtained high current efficiency values of approximately $90 \%$ in the wide range of plating time. These results indicate that the DES-based bath has industrial advantages for mass-producing Fe films. Therefore, we conclude that the DES-based bath is an attractive plating bath for Fe films. (C) 2014 AIP Publishing LLC. [http://dx.doi.org/10.1063/1.4870319]
\end{abstract}

\section{INTRODUCTION}

Electroplating is one of useful technique for obtaining of metallic magnetic films, and many researchers reported the films of the magnetic elements and their alloys, such as $\mathrm{Fe}-\mathrm{Ni}, \mathrm{Fe}-\mathrm{Co}, \mathrm{Fe}-\mathrm{Co}-\mathrm{Ni}$, Fe-Pt, and Co-Pt, prepared from aqueous solutions plating baths. ${ }^{1-7}$ Although the aqueous solution is one of commonly used for plating baths, a water reduction prevents us from plating some metals which have standard potentials less negative than the potential of water reduction. Although it is well-known that Fe-based magnetic alloys, such as Fe-Ni, Fe-Al-Si, Fe-Pt, and Nd-Fe-B, show good magnetic properties, some metals such as $\mathrm{Al}$ and $\mathrm{Nd}$ are difficult to obtain from aqueous solutions plating baths. In order to obtain the films of those metals, non-aqueous solutions are required, such as molten salts and organic solvents. $^{8-17}$ Recently, Deep Eutectic Solvents (DESs), which are a type of ionic solvents, have been gained much attention, ${ }^{18-20}$ and are expected as new non-aqueous solutions due to their high conductivity, wide potential window, high purity, and low cost. Some researchers electroplated metallic magnetic materials of $\mathrm{Ni}, \mathrm{Co}$, Ni-Co, Ni-Co-Sn, $\mathrm{Sm}-\mathrm{Co}$, and Co-Pt from DES-based baths and reported that potentials of DESs as future non-aqueous solutions. ${ }^{21-27}$ Hence, we expected that DESs enable us to obtain various types of Fe-based magnetic films by taking advantage of the wide potential window and focused on Fe films as a pre-stage of plating of the Fe-based films. In this study, we investigated the magnetic properties of Fe films plated in a DES-based bath and evaluated the productivity for the plating process.

\footnotetext{
${ }^{\text {a) }}$ Author to whom correspondence should be addressed. Electronic mail: t-yanai@nagasaki-u.ac.jp.
}

\section{EXPERIMENTAL PROCEDURES}

\section{A. Preparation of an electroplating bath}

We used choline chloride ( $\mathrm{ChCl}$ )-ethylene glycol (EG) types of DES based on the report that high current efficiency (>99\%) was obtained for Ni plating films. ${ }^{26,28}$ The DES was fabricated by stirring the mixture of $\mathrm{ChCl}$ and $\mathrm{EG}$ at $70^{\circ} \mathrm{C}$. We added $\mathrm{FeCl}_{2} \bullet 4 \mathrm{H}_{2} \mathrm{O}$ to the above-mentioned DES. The components of the electroplating bath are shown in Table I. We heated the bath up to target temperature and stirred the components until a homogeneous liquid state.

\section{B. Electroplating of Fe films}

We electroplated the Fe films using a direct current in the galvanostatic mode. $500 \mu$ m-thick and $5 \mathrm{~mm}$-wide $\mathrm{Fe}$ and $\mathrm{Cu}$ plates were used as the anode and the cathode electrodes, respectively. The distance between the electrodes was set at $20 \mathrm{~mm}$ and we obtained $75-\mathrm{mm}^{2} \mathrm{Fe}$ film on the Cu plate. The current density and the deposition time were controlled by a computer-aided dc current source (Takasago EX375L2). The bath temperature was changed from 50 to $140^{\circ} \mathrm{C}$. Details of the plating conditions are shown in Table II.

\section{Measurements}

The thicknesses and the hysteresis loops of the electroplated Fe films were measured with a micrometer (Mitutoyo CPM15-25MJ) and a vibrating sample magnetometer,

TABLE I. Components in the plating bath.

\begin{tabular}{ll}
\hline \hline Components & Weight $(\mathrm{g})$ \\
\hline Choline Chloride $(\mathrm{ChCl})$ & 10 \\
Ethylene Glycol $(\mathrm{EG})$ & 10 \\
$\mathrm{FeCl}_{2} \bullet 4 \mathrm{H}_{2} \mathrm{O}$ & 15 \\
\hline \hline
\end{tabular}


TABLE II. Electroplating conditions.

\begin{tabular}{lc}
\hline \hline Conditions & Values \\
\hline Bath temperature & $50-140{ }^{\circ} \mathrm{C}$ \\
Current density & $67,133 \mathrm{~mA} / \mathrm{cm}^{2}$ \\
Plating time & $2-20 \mathrm{~min}$ \\
\hline \hline
\end{tabular}

respectively. The thicknesses of the plated $75 \mathrm{~mm}^{2}$-films were determined by averaging the values obtained for approximately every $9 \mathrm{~mm}^{2}$ (9 points). The maximum applied field of approximately $1.5 \mathrm{MA} / \mathrm{m}$ was used for the measurements of the hysteresis loops. The surface morphology of the films was observed by means of SEM (Hitachi High-technologies S-3000). The current efficiency, which is the ratio of the actual amount of the deposited material to the theoretical amount, was calculated from the actual weight of the electroplated Fe film and the theoretical weight calculated by Faraday's law. We obtained the theoretical weight of the electroplated film assuming only the following reaction on the cathode:

$$
\mathrm{Fe}^{2+}+2 \mathrm{e} \rightarrow \mathrm{Fe}
$$

\section{RESULTS AND DISCUSSION}

Figure 1 shows SEM images of the films prepared at bath temperatures of 60 and $140{ }^{\circ} \mathrm{C}$. The deposition time and the current density were $20 \mathrm{~min}$ and $67 \mathrm{~mA} / \mathrm{cm}^{2}$, respectively. The Fe film plated at $60^{\circ} \mathrm{C}$ have smooth surfaces in spite of the fact that the bath includes no smoothing agents. For the Fe film plated at $140{ }^{\circ} \mathrm{C}$, small particles are observed on the surface of the film. From the result for the SEM observations, we found that the DES-based bath with much higher temperature is not suitable for industrial applications due to the rough surface of the film. Figure 2 shows the current efficiency as a function of the bath temperature. We obtained high current efficiency around a bath temperature of $100^{\circ} \mathrm{C}$, and low values of current efficiency were observed at lower or higher bath temperature regions. Generally, conductivity of DES depends on temperature and decreases with decrease
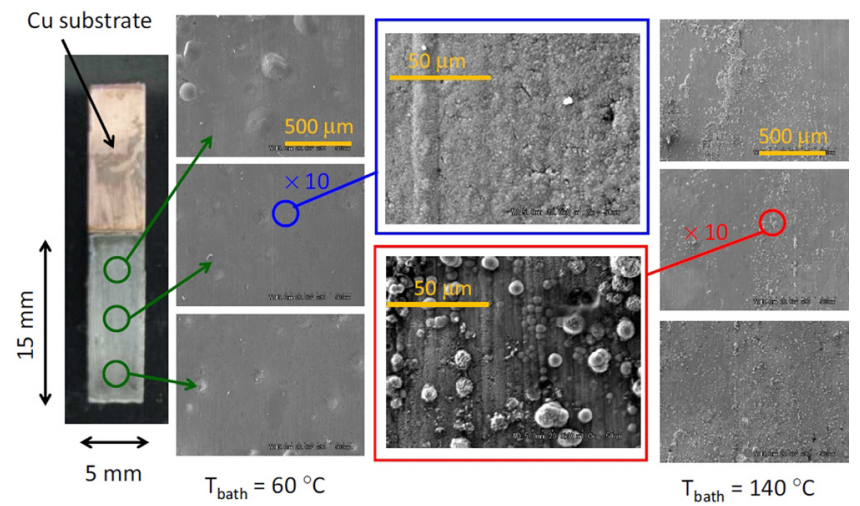

FIG. 1. Photograph and SEM images of the Fe film plated from a DESbased bath. The DES-based bath was prepared from $10 \mathrm{~g}$ of $\mathrm{ChCl}, 10 \mathrm{~g}$ of $\mathrm{EG}$, and $15 \mathrm{~g}$ of $\mathrm{FeCl}_{2} \cdot 4 \mathrm{H}_{2} \mathrm{O}$. The Fe film was electroplated for $20 \mathrm{~min}$ at $67 \mathrm{~mA} / \mathrm{cm}^{2}$. The bath temperature were 60 and $140{ }^{\circ} \mathrm{C}$.

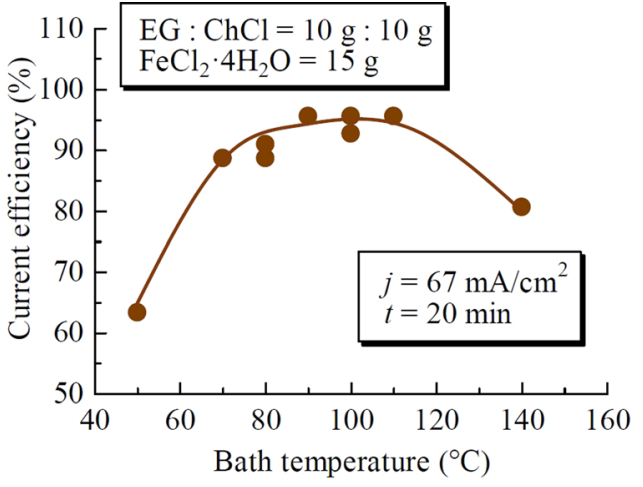

FIG. 2. Current efficiency as a function of bath temperature.

in the temperature. ${ }^{9}$ Since low conductivity prevents Fe ions in the bath from diffusing to the cathode, current efficiency decreases. Therefore, we consider that the film prepared at $50{ }^{\circ} \mathrm{C}$ showed low current efficiency by decrease in the conductivity of the DES. In the case of higher bath temperature, the small particles were segregated from the surface of the film during and/or after the plating. As the segregation reduced the weight of the plated film, low current efficiency was obtained in the film prepared at $140{ }^{\circ} \mathrm{C}$. From the results for the surface morphology and the current efficiency, we determined the bath temperature at $100{ }^{\circ} \mathrm{C}$ for the following experiments.

High deposition rate and high current efficiency are important factors for plating process since the required film thickness could be obtained in a short plating time. Therefore, we evaluated deposition rate and current efficiency for our plating process. Figure 3 shows the thickness of the electroplated Fe films as a function of the plating time. The bath temperature was set at $100^{\circ} \mathrm{C}$. In order to investigate the effect of the current density on the deposition rate, we plated the films at the current densities ( $j$ ) of 67 and $133 \mathrm{~mA} / \mathrm{cm}^{2}$. The thicknesses increased proportionately with the plating time. The deposition rates, which are calculated from the slope of the linear fitting lines, show high values of $57 \mu \mathrm{m} / \mathrm{h}$ for $j=67 \mathrm{~mA} / \mathrm{cm}^{2}$ and $119 \mu \mathrm{m} / \mathrm{h}$ for $j=133 \mathrm{~mA} / \mathrm{cm}^{2}$. We found that the deposition rate is enhanced in proportion to the current density.

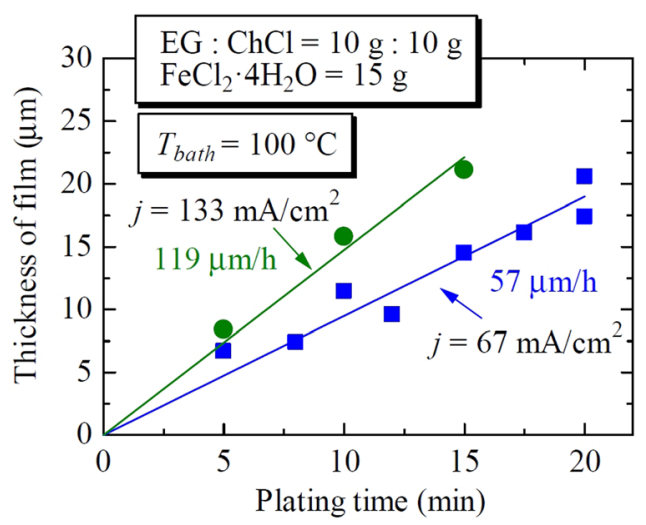

FIG. 3. Thicknesses of the electroplated Fe films as functions of plating time. The Fe films were electroplated at 67 and $133 \mathrm{~mA} / \mathrm{cm}^{2}$. 


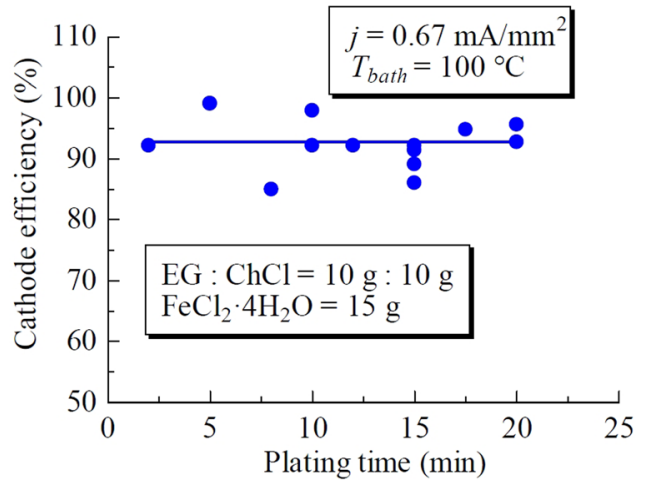

FIG. 4. Current efficiency of the electroplated Fe films as a function of plating time.

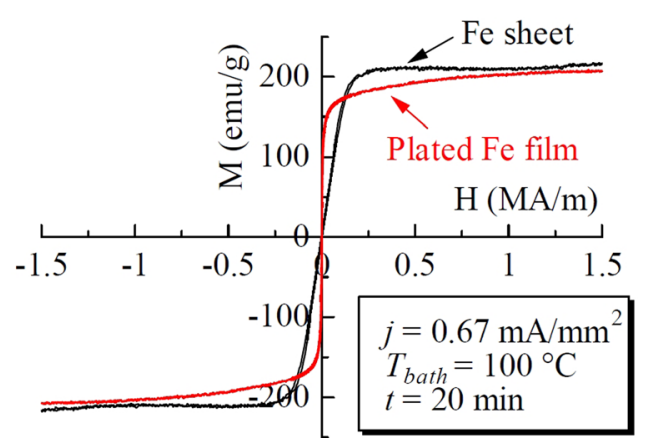

FIG. 5. Hysteresis loop of the electroplated Fe film prepared from a DESbased bath. A hysteresis loop of a commercial Fe sheet (purity: 99.5\%, dimension: $15 \mathrm{~mm} \times 5 \mathrm{~mm} \times 500 \mu \mathrm{m}$ ) is also shown for comparison.

Figure 4 shows the current efficiency as a function of the plating time. We confirmed that the DES-based bath has high current efficiency values of approximately $90 \%$.

Figure 5 shows a hysteresis loop of the Fe film. A hysteresis loop of a commercial Fe sheet (purity: 99.5\%, dimension: $15 \mathrm{~mm} \times 5 \mathrm{~mm} \times 500 \mu \mathrm{m}$ ) is also shown for comparison. As shown in Fig. 5, the film shows high spontaneous magnetization and the saturation magnetization of the film is comparable to that of the Fe sheet.

From these result, we found that ChCl-EG types of DES enables us to obtain several microns Fe thick-films in a short plating time.

\section{CONCLUSION}

In this study, we plated Fe films from a DES-based plating bath and investigated the magnetic properties of the Fe films. We also investigated the deposition rate and the current efficiency for the electroplating process. The obtained results are summarized as follows:

(1) Plating bath with higher temperature is not suitable to obtain Fe films with smooth surface.

(2) High current efficiency is obtained at a bath temperature around $100^{\circ} \mathrm{C}$.

(3) DES-based bath shows a high deposition rate $(>100 \mu \mathrm{m} / \mathrm{h})$.

(4) Current efficiency shows high value $(>90 \%)$ and almost constant in the wide range of plating time.

${ }^{1}$ T. Shimokawa, T. Yanai, K. Takahashi, M. Nakano, K. Suzuki, and H. Fukunaga, IEEE Trans. Magn. 48, 2907 (2012).

${ }^{2}$ C. Qianga, J. Xua, S. Xiaoa, Y. Jiao, Z. Zhanga, Y. Liua, L. Tiana, and Z. Zhoua, Appl. Surf. Sci. 257, 1371 (2010).

${ }^{3}$ T. Yanai, H. Uto, T. Shimokawa, M. Nakano, K. Suzuki, and H. Fukunaga, J. Korean Phys. Soc. 62, 1966 (2013).

${ }^{4}$ T. Osaka, M. Takai, K. Hayashi, K. Ohashi, M. Saito, and K. Yamada, Nature 392, 796 (1998).

${ }^{5}$ G. Zangari, P. Bucher, N. Lecis, P. L. Cavallotti, L. Callegaro, and E. Puppin, J. Magn. Magn. Mater. 157/158, 256 (1996).

${ }^{6}$ F. M. F. Rhen, G. Hinds, C. O'Reilly, and J. M. D. Coey, IEEE Trans. Magn. 39, 2699 (2003).

${ }^{7}$ N. Fujita, S. Maeda, S. Yoshida, M. Takase, M. Nakano, and H. Fukunaga, J. Magn. Magn. Mater. 272-276, e1895 (2004).

${ }^{8}$ W. Simka, D. Puszczyk, and G. Nawrat, Electrochim. Acta 54, 5307 (2009).

${ }^{9}$ T. Iida, T. Nohira, and Y. Ito, Electrochim. Acta 46, 2537 (2001).

${ }^{10}$ R. Andreescu and M. J. O'Shea, J. Appl. Phys. 91, 8183 (2002).

${ }^{11}$ H. Konish, T. Nohira, and Y. Ito, Electrochim. Acta 47, 3533 (2002).

${ }^{12}$ T. Iida, T. Nohira, and Y. Ito, Electrochim. Acta 48, 901 (2003).

${ }^{13}$ T. Iida, T. Nohira, and Y. Ito, J. Alloys Compd. 386, 207 (2005).

${ }^{14}$ J. Sayama, K. Mizutani, T. Asahi, J. Ariake, K. Ouchi, S. Mastunuma, and T. Osaka, J. Magn. Magn. Mater. 287, 239 (2005).

${ }^{15}$ B. Koo and B. Yoo, Surf. Coat. Technol. 205, 740 (2010).

${ }^{16}$ D. S. Yuan, G. K. Liu, and Y. X. Tong, J. Electroanal. Chem. 536, 123 (2002).

${ }^{17}$ G. R. Li, Y. X. Tong, and G. K. Liu, J. Electroanal. Chem. 562, 223 (2004).

${ }^{18}$ A. P. Abbott, D. Bothby, G. Capper, D. L. Davies, and R. Rasheed, J. Am. Chem. Soc. 126, 9142 (2004).

${ }^{19}$ A. P. Abbott, G. Capper, D. L. Davies, R. K. Rasheed, and V. Tambyrajah, Chem. Commun. 9, 70 (2003).

${ }^{20}$ A. P. Abbott, G. Capper, D. L. Davies, K. J. McKenzie, and S. U. Obi, J. Chem. Eng. Data 51, 1280 (2006).

${ }^{21}$ E. Gómez, P. Cojocaru, L. Magagnin, and E. Valles, J. Electroanal. Chem. 658, 18 (2011).

${ }^{22}$ P. Cojocaru, L. Magagnin, E. Gómez, and E. Valles, Mater. Lett. 65, 3597 (2011).

${ }^{23}$ H. Yang, X. Guo, N. Birbilis, G. Wu, and W. Ding, Appl. Surf. Sci. 257, 9094 (2011)

${ }^{24}$ P. Guillamat, M. Cortés, E. Vallés, and E. Gómez, Surf. Coat. Technol. 206, 4439 (2012).

${ }^{25}$ G. Saravanan and S. Mohan, J. Alloys Comp. 522, 162 (2012).

${ }^{26}$ Y. H. You, C. D. Gu, X. L. Wang, and J. P. Tu, Surf. Coat. Technol. 206, 3632 (2012).

${ }^{27}$ J. Vijayakumar, S. Mohan, S. A. Kumar, S. R. Suseendiran, and S. Pavithra, Int. J. Hydrogen Energy 38, 10208 (2013).

${ }^{28}$ A. P. Abbott, G. Capper, K. J. McKenzie, and K. S. Rayder, J. Electroanal. Chem. 599, 288 (2007). 